\section{Assessing the Oklo phenomenon}

Professor Alvin Weinberg, Director of Oak Ridge National Laboratory, Tennessee, comments on the lessons to be learned from the discovery of a natural reactor

THE Oklo River is a small stream that runs near the town of Mounana, Gabon; here there is a lange, open-pit, uraninite mine which I visited a few months ago. Oklo has become famous ever since French scientists of the Commissariat a L'Énergie Atomique discovered in 1972 that the mine was the site of ancient spontaneous chain reactors some $1.8 \times 10^{9}$ years ago. At that time the uranium-235 concentration was about $3 \%$, instead of its present $0.72 \%$. This is the same concentration now used in the fuel of modern pressurised water reactors. Indeed, the reactors at Oklo operated for about $15,000 \mathrm{MW}$ years-that is, the equivalent of 5 years of a modern $1,000 \mathrm{MW}$ reactor-and reached a burn-up of about $25,000 \mathrm{MW}$ days per ton of uranium, again about the same as is reached in a modern PWR.

The Oklo phenomenon is surely one of the most exciting scientific discoveries of the decade. I hope that it quickly becomes part of the common understanding not only of scientists, but also of laymen-just as Pithecanthropus Erectus or King Tutankhamen have become parts of the common, as well as the scientific, understanding. I am not unbiased in this desire. Despite all the fuss about nuclear energy, I am still an unabashed nuke. For me, the long-term alternatives to nuclear energy: solar energy (and its children -wind, waves, ocean thermal gradients, biomass), geothermal energy, and fusion are either too expensive (solar) or too small (geothermal) or too uncertain (fusion).

The path of conservation is all well and good for a developed country that has energy to conserve; it has little relevance for a country such as Gabon, or for that matter, most of the world that is bent on development. Nor can I take the talk about 'small is beautiful' or a "fission-free bridge to a solar future' fully seriously. Has anyone demonstrated on a scale large enough to make the experiment convincing, that small is really beautiful rather than simply poor? Or can anyone speak so confidently about future heavy dependence on fossil fuel with the $\mathrm{CO}_{2}$ in the atmosphere increasing at a rate of about $0.15 \%$ per year, probably because we are burning so much fossil fuel? No, it seems to me that nuclear energy will be necessary especially in the long run. The main job of the nuclear community at present then is to make nuclear energy acceptable-to construct a nuclear future that adequately deals with the shortcomings of nuclear energy-some real, some only imagined.

We are all familiar with the issues by now: proliferation, reactor safety, terrorism and sabotage, diversion, waste disposal. Of these issues, there is little question that in the public's mind, and indeed, in the minds of most scientists outside the nuclear community, waste disposal is the most serious concern. As long ago as 1952, James Conant, the president of the American Chemical Society, assented that the public would reject nuclear energy as not being worth the candle because the safe, permanent disposal of radioactive waste posed an insoluble problem. The recent Flowers report, on nuclear power and the environment, regards the problem of waste disposal as being in an unsatisfactory state. The new California law requires that a technology for permanent waste disposal must be demonstrated before reactors can be built there.

Until Oklo was discovered, permanent waste disposal in geologic formation seemed to be a problem that could not be solved in principle: since the wastes remain hazardous for thousands of years, one generation simply could not penform a definitive experiment. But Oklo has done much to change this. During the course of the chain reaction some five tons of fission

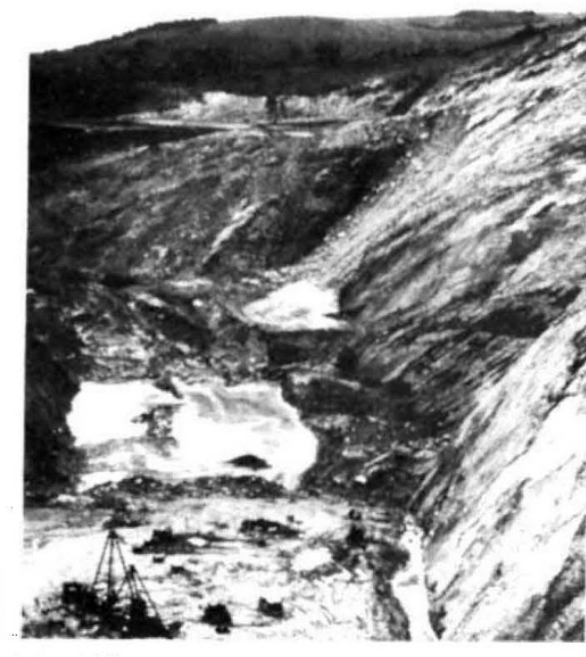

The Oklo site products and perhaps one-half this amount of plutonium and other transuranics were formed. Of the fission products, the gases, the alkalis and alkaline earths, and ruthenium disappeared. On the other hand, the rare earths and the plutonium, uranium, and presumably the other actinides, remained in place, within the limits of measurement (at least 80 per cent of the plutonium is accounted for). The strontium-90 probably decayed in place to zirconium-90; whatever leaching of alkaline earth fission products occurred took place over a time long compared to the 30-year half-life of the strontium-90.

Thus nature has performed the experiment, and the findings, on the whole, are reassuring. To be sure cesium-137, a soluble species, migrated from the site; on the other hand strontium-90 probably did not; and most important, the actinides, which pose the really long-term hazard (thousands rather than hundreds of years) remained in place.

Sceptics will still remain unconvinced; they wil argue that Oklo represented a special geologic situation, that we cannot be absolutely sure-and that anyhow, there really is something new and spooky about this whole radiation thing. This is the essence of the matter. I shall never forget Enrico Fermi, during one of the monthly information meetings we held in 1943 at the wartime Metallurgical Laboratory, reminding us that the unique significance of the chain reaction lay in its bringing mankind in contact with unprecedented amounts of radioactivity. Never mind that radiation has become one of the best, if not the best, understood physical insults to the biosphere. It nevertheles represents something most people are unfamiliar with and are therefore afraid of.

Unless our society accepts the reality of radiation, and the proposition that radioactivity can be safely sequestered, nuclear energy will founder. And this is why it is so important that Oklo become a household word. Fermi was not the first to achieve the chain reaction, nor was he the first to put large, concentrated amounts of radioactivity on earth. Nature had achieved this $1.8 \times 10^{9}$ years earlier. Although the Oklo event affected life in the immediate vicinity, our planet survived and the biosphere evolved. Perhaps 100 years from now, when we have become fully accustomed to man-made chain reactors, we will look back and wonder why so much fuss was made about the problem of radioactive waste disposal which nature had already demonstrated to be tractable. 